\title{
THA Improves Word Priming and Clonidine Enhances Fluency and Working Memory in Alzheimer's Disease
}

\author{
Paavo Riekkinen Jr., M.D., Ph.D., and Minna Riekkinen, M.D., Ph.D.
}

We investigated the effects of a single administration of a cholinesterase inhibitor, tetrahydroaminoacridine (THA, 25 and $50 \mathrm{mg}$, orally), and an $\alpha_{2}$-agonist, clonidine ( 0.5 and 2 $\mu \mathrm{g} / \mathrm{kg}$, orally), on neuropsychologic performance in two groups of patients with Alzheimer's disease ( $A D)$. Clonidine enhanced a spatial working memory and verbal fluency, but had no effect on spatial span or word priming. THA enhanced word priming, but had no effect on other performance measures. Our data suggests that degeneration of the LC noradrenergic

KEY WORDS: Frontal functions; Semantic Priming; Alzheimer's disease; $\alpha_{2}$-agonist; Cholinesterase inhibitor

Alzheimer's disease (AD) affects several different cognitive functions during relatively early stages of the disease. Declarative and procedural memories, and central executive functions are impaired compared with agematched controls (Wilcock and Esiri 1982; Shimamura et al. 1987; Becker 1988; Baddeley et al. 1991; Schwartz et al. 1996). Many investigations conducted with AD patients have focused on the pathologic correlates of impaired semantic and episodic declarative (i.e., memory that is available to conscious awareness) memory. Neurofibrillary tangles and cell loss in the entorhinal cortex and hippocampus, causing a pathologically rapid dependent forgetting of new episodic memories and an impaired ability to form novel semantic memo-

From the Department of Neuroscience and Neurology, University and University Hospital of Kuopio, Kuopio, Finland.

Address correspondence to: Paavo Riekkinen Jr., Dept. of Neuroscience and Neurology, University and University Hospital of Kuopio, Canthia Building, Kuopio, POB 1627, 70211, Finland.

Received January 21, 1998; revised July 20, 1998; accepted July 22, 1998. system and the cholinergic cells of the basal forebrain have different functional consequences during the progression of $A D$. Finally, a combined treatment with noradrenergic and cholinergic drugs might produce a qualitatively broader effect on cognitive functions than either of the treatments alone, and more effectively attenuate clinical dementia. [Neuropsychopharmacology 20:357-364; 1999] (C) 1999 American College of Neuropsychopharmacology. Published by Elsevier Science Inc.

ries (Squire 1987; Leonard et al. 1995; Bunsey and Eichenbaum 1996), can be detected at the early stage of the disease (Braak and Braak 1996). For example, degeneration of the hippocampus, as measured with volumetric magnetic resonance imaging (MRI) analysis, correlates with the inability to learn a supra-span list of words and with poor visual recognition memory performance after long delays in a delayed matching to sample test (Riekkinen et al. 1998). The progressive degeneration of the prefrontal association areas might be related to impaired central executive function and disrupt working memory, planning, and fluency (Borkowski et al. 1967; Baddeley et al. 1991; Rueckert et al. 1994; Baddeley 1996; Phelps et al. 1997). Performance of AD patients is more impaired at dual rather than single task conditions, indicating that central executive function is also decreased in AD patients (Baddeley et al. 1991).

There are only a few studies that have investigated the neurobiologic correlates of procedural memory in AD patients (Jelicic et al. 1995) and the effect of drug treatments on these types of memory failure (Schwartz et al. 1996). In $\mathrm{AD}$, the dysfunction of different forms of procedural memory are related to degeneration of specific cortical areas. Perceptual priming, mediated by ex- 
trastriate occipital visual association areas, and semantic priming, mediated by temporal or parietal association areas, are impaired in AD (Shimamura et al. 1987; Jelicic et al. 1995; Schwartz et al. 1996). For example, lexical priming ability, measured with the word stem completion test, indicated that AD patients benefited less from priming than controls (Shimamura et al. 1987). Other forms of procedural memory that depend on functioning of the basal ganglia, such as skill learning, however, are intact in AD patients (Heindel et al. 1989, 1991; Salmon and Butters 1995).

The importance of cholinergic cell loss in the basal forebrain in $\mathrm{AD}$ for the development of cognitive dysfunction and dementia is supported by several independent lines of research. First, post-mortem studies conducted with samples obtained from AD patients found a significant reduction in the activity of markers for cholinergic fibers in the cortex and hippocampus, and the severity of the cholinergic pathology correlates with the degree of dementia (Bowen et al. 1976; Whitehouse et al. 1982; Reinikainen et al. 1988). Second, cholinergic fibers in the frontal cortex and hippocampus are involved in the modulation of attention and memory in lower mammalian species and humans (Drachman et al. 1980; Kopelman and Corn 1988; Dunnett et al. 1991; Robbins et al. 1996). Administration of scopolamine, a muscarinic antagonist, to healthy volunteers impairs attention and memory, mimicking some of the cognitive defects observed in patients at an early stage of AD (Kopelman and Corn 1988). Finally, treatment of AD patients with the anticholinesterase drug, tetrahydroaminoacridine (THA), improves attention and attenuates the clinical severity of dementia, but has no effect on episodic or declarative memory functions, which depend on the function of the medial temporal lobe memory systems (Sahakian et al. 1993; Riekkinen et al. 1998). Furthermore, THA failed to attenuate the central executive dysfunction, as it had no effect on working memory or fluency performance in AD patients (Alhainen et al. 1991b; Sahakian et al. 1993).

Noradrenergic $\alpha 2$-agonists, such as clonidine and guanfacine, improve functioning of working memory via $\alpha 2 \mathrm{~A}$-adrenoceptors located at the principal sulcus in monkeys (Arnsten and Cai 1993; Arnsten et al. 1996). Similarly, administration of $\alpha 2$-agonists improves functions that depend on the prefrontal areas, such as spatial working memory and planning in human volunteers (Coull 1994; Coull et al. 1995). Furthermore, clonidine treatment attenuates defects of verbal fluency in Korsakoff's psychosis (Mair and McEntee 1986). These results suggest that administration of $\alpha 2$-agonists also enhances functioning of the prefrontal cortical mechanisms (Moffoot et al. 1994) and attenuates cognitive decline in $\mathrm{AD}$ patients. Also, the profile of action of $\alpha 2$-agonists might be different from that produced by an anticholinesterase drug, suggesting that a combina- tion of noradrenergic and cholinergic drugs could more effectively attenuate cognitive dysfunction.

The present study was designed to compare the effects of the $\alpha 2$-agonist, clonidine, and the anticholinesterase drug, THA, on functions dependent on prefrontal and temporo-parietal cortical regions. We administered clonidine or THA to AD patients and analyzed the effect of the treatments on functions that depend on the prefrontal (spatial working memory, verbal fluency, and spatial span) (Millner 1964) or temporo-parietal (semantic word priming) (Salmon and Butters 1995) systems.

\section{PATIENTS AND METHODS}

Thirty patients were included in the THA group and 20 patients were included in the clonidine group (Table 1). The patients fulfilled the NINCDS-ADRDA criteria of probable AD. The assessment of clinical severity of dementia, MRI, MRI-based volumetric analysis of the hippocampi and amygdala, and SPECT (ECD retention; THA study patients only) studies were used to support the clinical diagnosis of AD. The baseline neuropsychologic profile (Table 2) that was also used to support the diagnosis of $\mathrm{AD}$ consisted of an assessment of verbal skills (Boston Naming test, Vocabulary subtest of the Wechsler Adult Intelligence Scale), visuo-constructive skills (copy a cube, clock setting, Block design of the Wechsler Adult Intelligence Scale), praxis, executive function [Trail Making test (TMT) A and C, Verbal/Category Fluency], and immediate and delayed recall (list learning, Wechsler Logical Memory Test; Story recall A \& B). In the TMT version A and C, the subject's score was the time required to complete each trial. Three to four days after the baseline neuropsychologic examinations, the drug study was started. Routine blood and cerebrospinal fluid laboratory tests were used to exclude secondary dementia. Hamilton scales were used to exclude depression and Hachinski scales were used to exclude vascular pathology.

During the study period, 42 patients were free of any CNS active medication. Eight AD patients had a low dose of neuroleptic medication and had been on a sta-

Table 1. AD Patients involved in the Clonidine and Tetrahydroaminoacridine Studies Did Not Differ in Mean Age, Disease Duration (mean \pm SD), or Sex Distribution

\begin{tabular}{lcc}
\hline \multicolumn{2}{c}{ Treatment } \\
\cline { 2 - 3 } & $\begin{array}{c}\text { Tetrahydroaminoacridine } \\
(\boldsymbol{n}=\mathbf{3 0})\end{array}$ & $\begin{array}{c}\text { Clonidine } \\
(\boldsymbol{n}=\mathbf{2 0})\end{array}$ \\
\hline Age & $67.2 \pm 3.3$ & $66.6 \pm 3.1$ \\
Disease duration & $4.6 \pm 0.7$ & $4.8 \pm 0.8$ \\
Male/female & $10 / 20$ & $6 / 14$ \\
\hline
\end{tabular}


Table 2. Baseline neuropsychologic performance of the AD patients involved in the clonidine and THA studies $($ mean $\pm \mathrm{SD})$

\begin{tabular}{|c|c|c|}
\hline \multirow[b]{2}{*}{$\begin{array}{l}\text { Performance } \\
\text { Measures }\end{array}$} & \multicolumn{2}{|c|}{ Treatment Group } \\
\hline & $\begin{array}{l}\text { Tetrahydroaminoacridine } \\
\qquad(n=30)\end{array}$ & $\begin{array}{l}\text { Clonidine } \\
(n=20)\end{array}$ \\
\hline \multicolumn{3}{|l|}{ Executive functions } \\
\hline Category fluency & $11.0 \pm 3.9$ & $9.9 \pm 4.0$ \\
\hline TMT A (s) & $101 \pm 55$ & $107 \pm 76$ \\
\hline Errors & $1.2 \pm 0.3$ & $1.5 \pm 0.5$ \\
\hline TMT C (s) & $214 \pm 45$ & $229 \pm 35$ \\
\hline Errors & $2.0 \pm 0.9$ & $2.2 \pm 0.9$ \\
\hline \multicolumn{3}{|l|}{ Immediate recall } \\
\hline \multicolumn{3}{|l|}{ Story recall } \\
\hline A & $4.1 \pm 2.1$ & $4.4 \pm 1.5$ \\
\hline B & $4.0 \pm 1.9$ & $2.2 \pm 1.9$ \\
\hline \multicolumn{3}{|l|}{ Delayed recall } \\
\hline \multicolumn{3}{|l|}{ List learning } \\
\hline Story recall & $1.0 \pm 0.9$ & $0.7 \pm 0.6$ \\
\hline A & $1.0 \pm 0.4$ & $1.3 \pm 1.1$ \\
\hline B & $0.9 \pm 1.1$ & $0.9 \pm 1.1$ \\
\hline \multicolumn{3}{|l|}{$\begin{array}{c}\text { Visuoconstructive } \\
\text { functions }\end{array}$} \\
\hline Copy figures & $14.8 \pm 4.5$ & $8.3 \pm 6.5^{*}$ \\
\hline Clock setting & $6.0 \pm 3.2$ & $9.7 \pm 1.3^{* * *}$ \\
\hline Block design & $12.1 \pm 6.5$ & $14.4 \pm 6.0$ \\
\hline Praxic functions & $41.3 \pm 4.7$ & $33.1 \pm 5.8^{*}$ \\
\hline \multicolumn{3}{|l|}{ Verbal functions } \\
\hline Boston naming & $12.5 \pm 4.9$ & $13.2 \pm 3.0$ \\
\hline Vocabulary & $17.1 \pm 6.4$ & $16.0 \pm 6.9$ \\
\hline MMSE & $21.9 \pm 2.4$ & $20.0 \pm 2.7$ \\
\hline ADAS-cog & $23.5 \pm 5.6$ & $21.4 \pm 5.6$ \\
\hline
\end{tabular}

Abbreviations: ADAS $\operatorname{cog}=$ Alzheimer disease assessment scale, $\operatorname{cog}$ nitive subscale; $\mathrm{MMSE}=$ mini mental status examination; $\mathrm{TMT}=$ trail making test.

${ }^{a}$ No constant group differences were found.

${ }^{*} p<.05$ worse than the THA group.

${ }^{* *} p<.05$ better than the THA group.

ble dose level for a minimum of 2 months before initiation of the study.

The local ethics committee and the national drug regulatory authorities reviewed and accepted the study plan. The patients, their caregivers, and the controls gave written informed consent for participation in the study.

\section{THA Treatment}

The study had a double blind design. THA (Takin ${ }^{\circledR}$, Astra, Sweden) 25 or $50 \mathrm{mg}$, and placebo capsules were similar looking and were orally administered to study patients $90 \mathrm{~min}$ before the neuropsychologic testing. We used a Latin Square design (placebo, THA $25 \mathrm{mg}$, THA $50 \mathrm{mg}$ ). A 5- to 7-day recovery was allowed between the different dose levels. The dose range was selected based on two earlier studies indicating that THA $50 \mathrm{mg}$ attenuates cortical EEG slowing in some of the
AD patients (Alhainen et al. 1991a; Riekkinen et al. $1997 \mathrm{~b})$. A smaller dose ( $25 \mathrm{mg}$ ) was also tested to evaluate the therapeutic window of acute THA administration for improvement of cognitive functions. Acute treatment with higher doses were not tested, as we earlier observed gastrointestinal side effects (diarrhea, nausea) in some AD patients when administered THA $75 \mathrm{mg}$.

\section{Clonidine Treatment}

The study had a double blind design. Clonidine (Catapressan ${ }^{\circledR}$, Boehringer-Ingelheim, Germany) .5 or $2 \mu \mathrm{g} /$ $\mathrm{kg}$ and placebo capsules were similar looking and were orally administered to study patients $90 \mathrm{~min}$ before the neuropsychologic testing. A Latin Square design was used (placebo, clonidine .5 or $2 \mu \mathrm{g} / \mathrm{kg}$ ). A 5- to 7-day recovery was allowed between the different dose levels. The dose range was selected based on previous evidence indicating that clonidine at this dose range modulates cognitive functions and blood pressure in healthy volunteers (Coull et al. 1995).

\section{Monitoring of Blood Pressure}

The blood pressure of subjects included in the clonidine group was measured before they received the study drugs or matching placebo tablets, $90 \mathrm{~min}$ afterwards (i.e., just before beginning of the test session), and after completion of the test session which lasted for 60 to $90 \mathrm{~min}$.

\section{Analysis of THA and Clonidine Treatments on Cognitive Functions}

During the word priming task subjects were asked to read eight words (e.g., motelli, pidätys) and to rate how much they liked each word on a 5-point scale. Two additional words were placed at the beginning of the list and three at the end to reduce primacy and recency effects. The words were presented for the study without explicitly telling subjects to expect a memory test. Following a single presentation of the words, subjects were shown 16 three-letter word stems and were asked to complete each stem with the first word that came to mind (e.g., mot, pid). There were always at least 10 possible words that could be used to complete each target stem, only one of which was presented for the study. Ten of the stems could be completed using study words, and the other eight stems were used to assess baseline guessing rates. The stems used to assess baseline rates were used as target stems for other subjects. The entire procedure was then repeated in exactly the same manner using a different list of 10 words.

In the verbal fluency test, patients were instructed to produce as many words that started with letter $\mathrm{P}, \mathrm{A}$, or 
$\mathrm{S}$ as they could in $60 \mathrm{~s}$. A forward spatial span test was used. A self-ordered search test of working memory, which incorporates a strategic search component to tax "central executive" function, was also used (Owen et al. 1990). Subjects had to search through a number of boxes (six or eight) for a hidden token without returning to a box that they had already examined on the same trial (to avoid within-search errors) or that had already contained a token in the previous trial (to avoid betweensearch errors). Tokens were hidden one at a time, and were never hidden in the same box twice. The numbers of each type of error at each level of difficulty were measured. The results of the six and eight box levels were pooled together for the analysis.

The tests had three parallel versions that were used during the different sessions.

\section{Statistics}

A repeated measures analysis of variance (ANOVA) followed by contrast analysis was used to analyze the treatment-induced changes in neuropsychologic performance of the different groups. Correlations between the biological markers (MRI and SPECT) and neuropsychologic scoring were analyzed with Pearson's correlation test.

\section{RESULTS}

\section{Word Priming}

A significant treatment effect was observed in priming ability measured after placebo or THA 25 or $50 \mathrm{mg}$ treatments $(\mathrm{F}(2,58)=11.52, p<.001$; (Figure 1A; Table 3). Contrast analysis revealed that THA dose-dependently increased priming $(t=3.74, p<.001$; Figure $1 \mathrm{~A})$. Clonidine $(0.5$ and $2 \mu \mathrm{g} / \mathrm{kg})$ treatment failed to improve word priming $(\mathrm{F}(2,38)=.9, p>.1)$ (Figure $1 \mathrm{~B}$; Table 3). THA and clonidine failed to affect baseline guessing rates $(\mathrm{F}(2,38)(2,58)<.4, p>.1$, for both; Figure 1A and B).

\section{Working Memory, Fluency, and Span}

THA failed to enhance spatial working memory (Figure $2 \mathrm{~A})$, fluency, or spatial span $(\mathrm{F}(2,58)=0.3, p>0.1$; Table 3$)$.

Clonidine 0.5 and $2 \mu \mathrm{g} / \mathrm{kg}$ treatment decreased between and within search errors in the spatial working memory tests $(\mathrm{F}(2,38)>19, p<.001$; Figure 2B; Table $3)$. A contrast analysis revealed that the effect of clonidine was larger at $2 \mu \mathrm{g} / \mathrm{kg}$ than at $0.5 \mu \mathrm{g} / \mathrm{kg}(t=-6.1$, $p<.001$ ). Clonidine also increased word fluency (Hottelings: $\mathrm{F}(2,18)=7.8, p<.01)$ and the higher dose was more effective than the lower dose for enhancing fluency $(t=-3.0, p<.001)$ (Table 3). Clonidine, however, failed to affect spatial span $(\mathrm{F}(2,38)=.4, p>.1$; Table 3$)$.
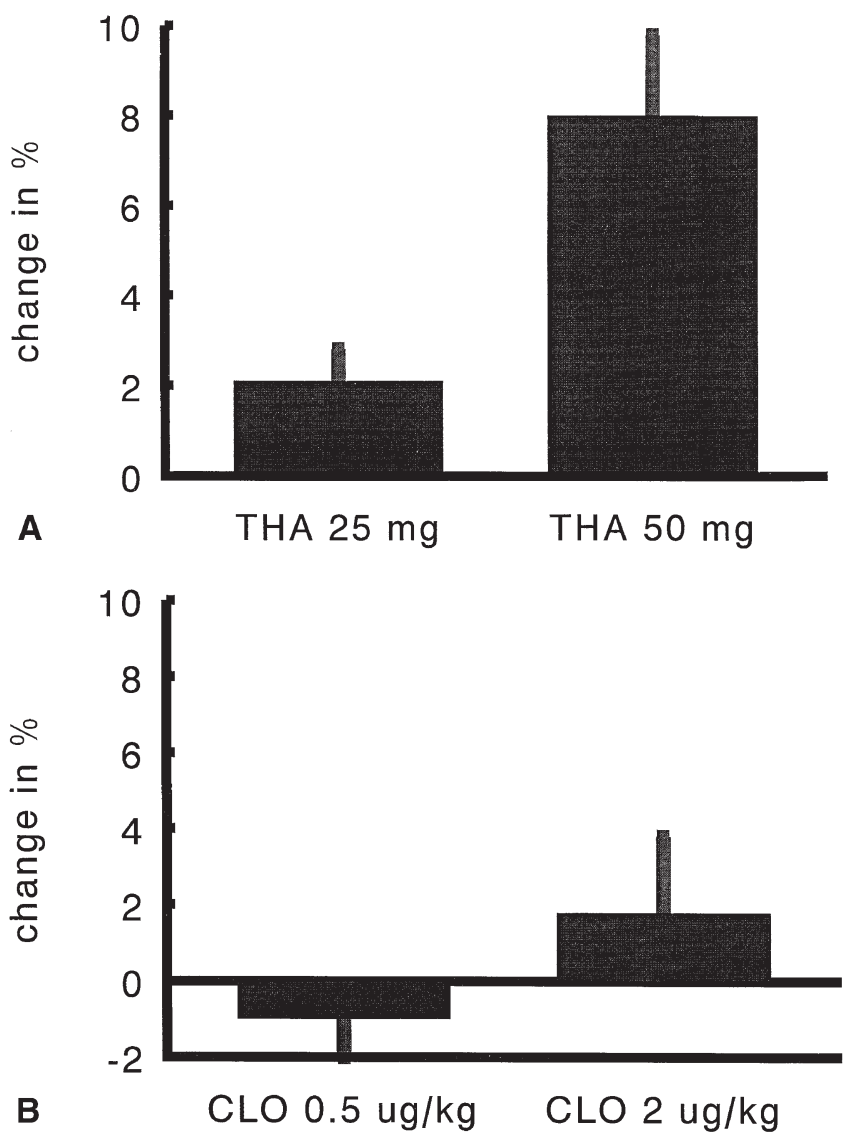

Figure 1. Lexical word priming ability was analyzed using the word completion tasks. Patients were shown words (e.g., motelli) and later asked to complete three-letter word stems with the first word that came to mind. The patients were not instructed to memorize the words when the words were shown for the first time. The baseline guessing rate (i.e., the tendency to complete the same words under conditions when they had not been presented) was also analyzed. The $y$-axis indicates the difference between placebo and treatment conditions in the percent of three-letter word stems completed with the study words. The bars represent group mean \pm SEM. (A) THA (25 and $50 \mathrm{mg}$ ) improved word priming measured with the word stem completion test in AD patients, but (B) clonidine (0.5 and $2 \mu \mathrm{g} / \mathrm{kg}$ ) did not improve word priming. THA and clonidine did not affect baseline guessing rates.

\section{Blood Pressure in Clonidine-Treated Patients}

Clonidine $2 \mu \mathrm{g} / \mathrm{kg}$ slightly decreased systolic blood pressure measured immediately before and after cognitive testing, but failed to affect diastolic blood pressure [systolic: $\mathrm{F}(2,38)=10.2, p<0.001$; diastolic: $\mathrm{F}(2,38)=$ $0.55, p>0.1$; systolic/diastolic $\mathrm{mm} \mathrm{Hg}$; immediately before and after testing: placebo: 137/90 and 135/91, clonidine $0.5 \mu \mathrm{g} / \mathrm{kg} \mathrm{135/90}$ and 1340/93; clonidine 2 $\mu \mathrm{g} / \mathrm{kg}: 133 / 91$ and 129/91]. 
Table 3. Neuropsychologic performance of the AD patients in spatial working memory, word fluency, spatial span, and word priming tests after placebo and clonidine or placebo and THA treatment. ${ }^{a}$

\begin{tabular}{|c|c|c|c|c|c|c|}
\hline \multirow[b]{3}{*}{ Performance Task } & \multicolumn{6}{|c|}{ Treatment } \\
\hline & \multicolumn{3}{|c|}{$\begin{array}{l}\text { Tetrahydroaminoacridine (mg) } \\
\qquad(n=30)\end{array}$} & \multicolumn{3}{|c|}{$\begin{array}{l}\text { Clonidine }(\mu \mathrm{g} / \mathrm{kg}) \\
\quad(n=20)\end{array}$} \\
\hline & Placebo & THA 25 & THA 50 & Placebo & Clo 0.5 & Clo 2.0 \\
\hline Baseline guessing & $7.6 \pm 5.1$ & $6.6 \pm 8.3$ & $6.6 \pm 6.3$ & $7.3 \pm 6.3$ & $8.6 \pm 5.9$ & $7.7 \pm 5.7$ \\
\hline $\begin{array}{l}\text { Word priming } \\
\text { Spatial working memory }\end{array}$ & $16.6 \pm 6.4$ & $18.6 \pm 6.3$ & $24.4 \pm 5.1^{*}$ & $15.3 \pm 4.2$ & $13.8 \pm 6.7$ & $16.7 \pm 7.4$ \\
\hline Within search errors & $7.8 \pm 3.1$ & $8.3 \pm 3.5$ & $7.9 \pm 1.9$ & $8.3 \pm 2.5$ & $8.4 \pm 2.7$ & $4.8 \pm 3.1^{* *}$ \\
\hline Between search errors & $58.9 \pm 24.2$ & $60.9 \pm 26.5$ & $62.4 \pm 16.9$ & $62.2 \pm 23.3$ & $59.6 \pm 24.5$ & $54.4 \pm 23.3^{* *}$ \\
\hline Spatial span & $4.7 \pm 0.9$ & $4.9 \pm 0.7$ & $5.0 \pm 0.9$ & $4.8 \pm 0.7$ & $5.0 \pm 0.5$ & $5.1 \pm 0.9$ \\
\hline Verbal fluency & $21.9 \pm 6.1$ & $20.7 \pm 8.8$ & $22.1 \pm 9.7$ & $21.3 \pm 6.9$ & $22.9 \pm 5.0$ & $24.8 \pm 4.8^{* *}$ \\
\hline
\end{tabular}

${ }^{a}$ Lexical word priming ability was analyzed using the word completion task. Patients were shown words (e.g., motelli) and later asked to complete three-letter word stems with the first word that came to mind. The patients were not instructed to memorize the words when the words were shown for the first time. The baseline guessing rate (i.e., the tendency to complete the same words under conditions when they had not been presented) was also analyzed. The values indicate the percent of three-letter word stems completed with the study words. Spatial working memory was measured by counting the within and between search errors. The values indicate the number of errors. In the verbal fluency test, the patients produced as many words that started with letter A, P, or S as they could in $60 \mathrm{~s}$. The values indicate the number of words generated. A forward spatial span was used. The number of correct responses is shown. All the values are group mean $\pm \mathrm{SD}$. Clonidine decreased errors in the spatial working memory test and increased words produced in the fluency test. In contrast, THA improved word priming.

${ }^{*} p<.05$ for THA induced improvement of performance.

$* * p<.05$ for clonidine induced improvement in performance.

\section{DISCUSSION}

In the present study, administration of THA and clonidine enhanced different cognitive functions in AD patients. THA improved word priming, but had no effect on spatial working memory or verbal fluency. Clonidine facilitated spatial working memory and verbal fluency, but failed to stimulate word priming. These results suggest that modulation of locus coeruleus (LC) noradrenergic cells might affect central executive function of the prefrontal cortex (Baddeley et al. 1991) and basal forebrain cholinergic systems might affect the parietal lexical priming systems (Salmon and Butters 1995).

The present result indicating that THA treatment improves word priming and the earlier reports describing an improvement of attention (Sahakian et al. 1993; Riekkinen et al. 1997a) suggest that THA treatment attenuates some of the cortical dysfunctions found in AD patients. Sahakian et al. (1993) reported that chronic treatment with THA improved attention at the same doses that attenuated the severity of clinical dementia. Riekkinen et al. (1997a) described that single administration of THA stimulated attention performance of $\mathrm{AD}$ patients that did not have a severe dysfunction of prefrontal areas, as measured by neuropsychologic scoring and SPECT ECD retention of the prefrontal area. Furthermore, we replicated earlier findings that working memory and fluency are not markedly improved by THA treatment (Sahakian et al. 1993). This indicates that THA stimulates attentional functions that also require functioning of the prefrontal areas, but does not improve spatial working memory and word fluency sensitive to frontal lesions. Therefore, it is possible that treatment of $\mathrm{AD}$ patients with an anticholinesterase drug might more effectively remediate functioning of prefrontal areas involved in attention, than working memory or fluency.

A comparison of the present results with previous results (Sahakian et al. 1993; Riekkinen et al. 1998) suggests that THA treatment cannot enhance declarative memory function, but improves performance in a test of conceptual word priming that is supposed to measure implicit memory (Squire 1987). Indeed, THA treatment fails to improve performance of AD patients in tests of declarative memory, such as paired associates learning, delayed matching to sample, and story recall, which depend on the functioning of the medial temporal lobe memory system (Sahakian et al. 1993; Riekkinen et al. 1998). Previous neuropsychologic evidence suggests that THA facilitates word priming by improving implicit memory processing in the temporo-parietal areas. Shimamura et al. (1987) initially found that AD patients can complete word stems with words, so that mental slowness or lack of attention to instructions cannot explain the defective word priming. Furthermore, baseline guessing rates were not reduced, indicating that AD patients did not fail because of the use of obscure of unusual words. Because the drug treatment was "on" during all stages of implicit memory testing, we cannot speculate whether encoding, storage, retrieval, or all were improved by THA treatment. We previously found that THA facilitates immediate recall of an actively memorized supra-span word list by improving attention in a few AD patients (Riekkinen et al. 


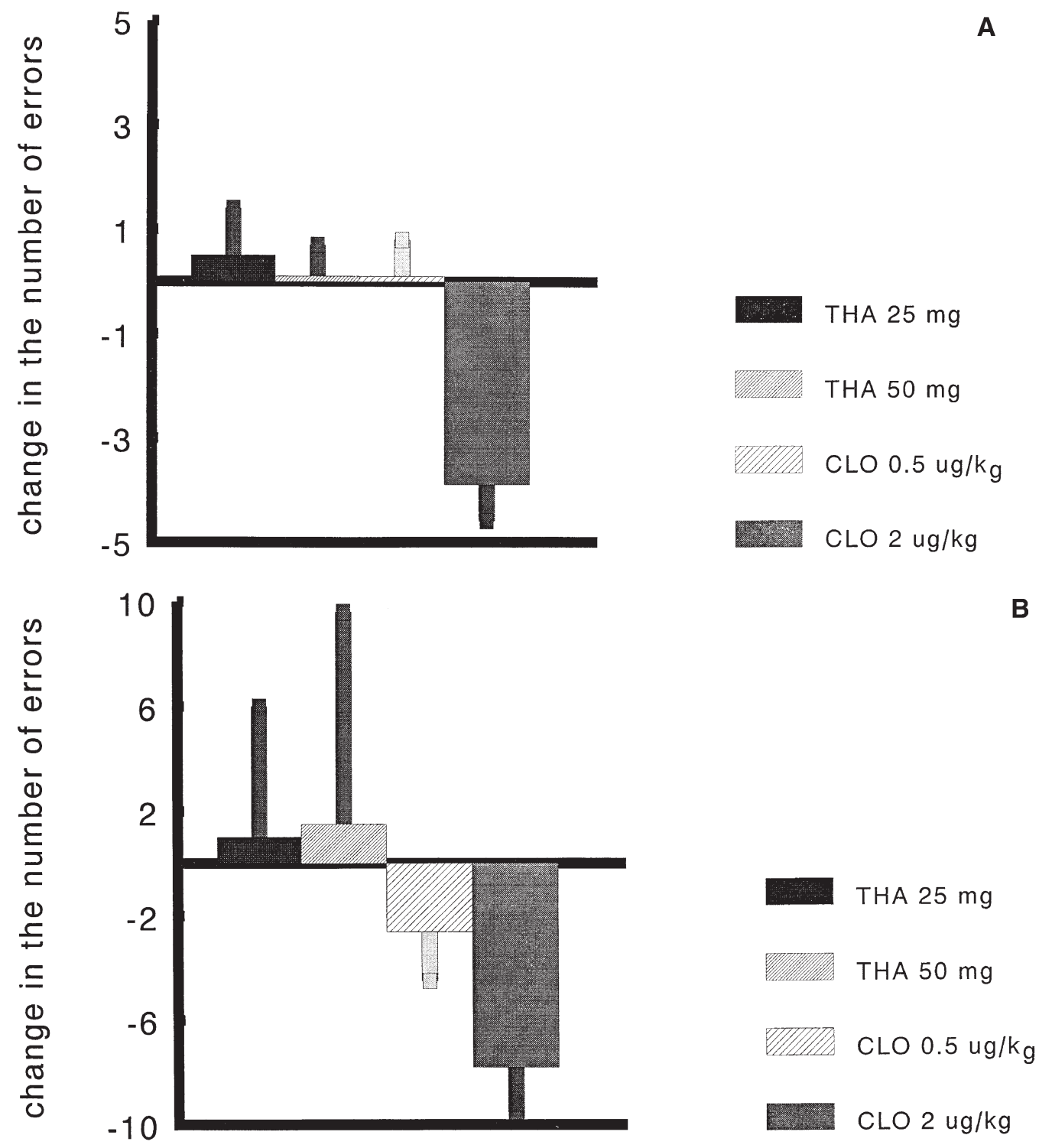

Figure 2. Spatial working memory was measured by analyzing the number of errors made during the working memory testing. THA (25 and $50 \mathrm{mg}$ ) had no effect on performance in spatial working memory test (A, B). Spatial working memory was improved in $\mathrm{AD}$ patients by clonidine $(0.5$ and $2 \mu \mathrm{g} / \mathrm{kg})$ treatment dose-dependently (A, B). Y-axis: the difference in the number of within and between search errors placebo and treatment conditions. The bars represent group mean \pm SEM.

1998). Due to severe disruption of the medial temporal lobe memory system, THA failed to stimulate free recall or recognition of these words after a 6-min break (Riekkinen et al. 1998). Therefore, the present data showing that the effect of THA on word priming is observed after a 6-min break further supports the idea that the action of an anticholinesterase drug on implicit memory is not mediated via medial temporal lobe memory systems.

Clonidine improved performance in word fluency and spatial working memory tests that depend on prefrontal functioning, but had no effect on word priming. It is relevant to note that previous pharmacologic studies in animals suggest that cognition-enhancing effects of $\alpha 2$-agonists are mediated by post-synaptic $\alpha 2$-adreno- ceptors (Arnsten et al. 1996). Indeed, in monkeys the ability of different $\alpha 2$-agonists to improve spatial working memory correlated with high relative $\alpha 2 \mathrm{~A}$ vs. $\alpha 2 B$ or $\mathrm{C}$ affinity, suggesting that postsynaptic $\alpha 2 \mathrm{~A}$-adrenoceptors in the prefrontal cortex mediate the action of subtype non-selective agonists on cognitive functions (Arnsten et al. 1996). Recent studies have also investigated the effects of $\alpha 2$-agonists on information processing in healthy humans, and these studies have described an improvement in spatial working memory (Coull et al. 1995). Furthermore, a previous study reported that acute administration of clonidine improves word fluency and increases anterior cingulate blood flow in Korsakoff's psychosis (Mair and McEntee 1986; 
Moffoot et al. 1994). The involvement of $\alpha 2$-adrenoceptors in the improvement of fluency and spatial working memory observed in AD (the present study) and Korsakoff's psychosis or in healthy volunteers is supported by a recent report describing the effect of idazoxan, an $\alpha 2$-antagonist, on cognition (Goodwin et al. 1997). Goodwin et al. (1997) found that idazoxan treatment disrupted spatial working memory and word fluency in $\mathrm{AD}$ patients, and that the reduction in blood flow in the lateral prefrontal area correlated with impaired fluency performance. Importantly, Mohr et al. (1989) reported that clonidine given for 2 weeks had no beneficial or adverse effects on neuropsychologic performance in $\mathrm{AD}$ patients. The differences between the neuropsychologic tests employed in the present study and those used in the previous study (Mohr et al. 1989) might explain the different results. First, Mohr et al. (1989) did not measure spatial working memory, but assessed verbal and visuospatial associative memory tests that might be less sensitive to the effects of clonidine. Second, Mohr et al. (1989) assessed neuropsychologic performance after 2 weeks of treatment, and as a compensatory change, a tolerance might have developed to the effects of clonidine.

In conclusion, activation of $\alpha 2$-adrenoceptors by clonidine improves frontal functions, such as spatial working memory and word fluency. In contrast, modulation of cholinergic transmission by the anticholinesterase drug, THA, improved word priming mediated via parietal areas. Therefore, our data suggests that degeneration of the LC noradrenergic system and the cholinergic cells of the basal forebrain have different functional consequences during the progression of $\mathrm{AD}$. Finally, a combined treatment with noradrenergic and cholinergic drugs might produce a qualitatively broader effect on cognitive functions than either of the treatments alone, and more effectively attenuate clinical dementia.

\section{REFERENCES}

Alhainen K, Partanen J, Reinikainen K, Laulumaa V, Soininen H, Airaksinen M, Riekkinen P (1991a): Discrimination of tetrahydroaminoacridine responders by a single dose pharmaco-EEG in patients with Alzheimer's disease. Neurosci Lett 127:113-116

Alhainen K, Riekkinen P Sr, Helkala E-L, Partanen J, Laulumaa V, Reinikainen $\mathrm{K}$, Soininen $\mathrm{H}$, Airaksinen $\mathrm{M}$ (1991b): The effect of THA on cognitive functions and spectral power EEG in Alzheimer's disease: preliminary results of an open study. In Iqbal K, McLachlan D, Winblad B, Wisniewski HM (eds), Alzheimer's Disease: Basic Mechanisms, Diagnosis and Therapeutic Strategies. Chichester, John Wiley \& Sons, pp 611-619

Arnsten AF, Cai JX (1993): Postsynaptic alpha-2 receptor stimulation improves memory in aged monkeys: Indi- rect effects of yohimbine versus direct effects of clonidine. Neurobiol Aging 14:597-603

Arnsten AF, Steere JC, Hunt RD (1996): The contribution of alpha 2-noradrenergic mechanisms of prefrontal cortical cognitive function. Potential significance for attentiondeficit hyperactivity disorder. Arch Gen Psychiatry 53:448-455

Baddeley A (1996): The fractionation of working memory. Proc Natl Acad Sci 93:13468-13472

Baddeley AD, Della Salla S, Spinnler H (1991): The two-component hypothesis of memory deficit in Alzheimer's disease. J Clin Exp Neuropsychol 13:372-380

Becker JT (1988): Working memory and secondary memory deficits in Alzheimer's disease. J Clin Exp Neuropsychol 10:739-753

Borkowski JG, Benton AL, Spreen O (1967): Word fluency and brain damage. Neuropsychologia 5:135-140

Bowen DM, Smith CB, White P, Davison AN (1976): Neurotransmitter related enzymes and indices of hypoxia in senile dementia and other abiotrophies. Brain 99:459496

Braak H, Braak E (1996): Evolution of the neuropathology of Alzheimer's disease. Acta Neurol Scand 165 (Suppl):3-12

Bunsey M, Eichenbaum H (1996): Conservation of hippocampal memory function in rats and humans. Nature 379:255-257

Coull JT (1994): Pharmacological manipulations of the alpha 2-noradrenergic system. Effects on cognition. Drugs and Aging 5:116-126

Coull JT, Middleton HC, Robbins TW, Sahakian BJ (1995): Contrasting effects of clonidine and diazepam on tests of working memory and planning. Psychopharmacology 120:311-321

Drachman DA, Noffsinger D, Sahakian BJ, Kurdziel S, Flemming P (1980): Aging, memory, and the cholinergic system: A study of dichotic listening. Neurobiol Aging $1: 39-43$

Dunnett SB, Barry JE, Robbins T (1991): The basal forebraincortical cholinergic system: Interpreting the functional consequences of excitotoxic lesions. Trends Neurosci 14:494-501

Goodwin GM, Conway SC, Peyro Saint Paul H, Glabus M, O'Carroll RE, Ebmesier KP (1997): Executive function and uptake of $99 \mathrm{mTc}$-exametazine shown by single photon emission tomography after oral idazoxan in probable Alzheimer-type dementia. Psychopharmacology 131:371-378

Heindel WC, Salmon DP, Shults CW, Walicke PA, Butters N (1989): Neuropsychological evidence for multiple implicit memory systems: A comparison of Alzheimer's, Huntington's, and Parkinson's disease patients. J Neurosci 9:582-587

Heindel WC, Salmon DP, Butters N (1991): The biasing of weight judgments in Alzheimer's and Huntington's disease: A priming or programming phenomenon. J Clin Exp Neuropsychol 13:189-203

Jelicic M, Bonebakker AE, Bonke B (1995): Implicit memory performance of patients with Alzheimer's disease: A brief review. Int Psychogeriatr 7:385-392 
Kopelman MD, Corn TH (1988): Cholinergic "blockade" as a model for cholinergic depletion. Brain 111:1079-1110

Leonard BW, Amaral DG, Squire LR, Zola-Morgan S (1995): Transient memory impairment in monkeys with bilateral lesions of the entorhinal cortex. J Neurosci 15:56375659

Mair RG, McEntee WJ (1986): Cognitive enhancement in Korsakoff's psychosis by clonidine: A comparison with 1-dopa and ephedrine. Psychopharmacology 88:444-457

Millner B (1964): Some effects of frontal lobectomy in man. In Warren JM, Akert K (eds), The Frontal Granular Cortex and Behavior. New York, McGraw-Hill, pp 313-331

Moffoot A, O'Carroll RE, Murray C, Dougall N, Ebmeier K, Goodwin GM (1994): Clonidine infusion increases uptake of $99 \mathrm{~m}$-Tc-exametazine in anterior cingulate cortex psychosis in Korsakoff psychosis. Psychological Medicine 24:53-61

Mohr E, Schlegel J, Fabbrini G, Williams J, Mouradian MM, Mann UM, Claus JJ, Fedio P, Chase TN (1989): Clonidine treatment of Alzheimer's disease. Arch Neurol 46:376-378

Owen AM, Downes JJ, Sahakian BJ, Polkey CE, Robbins TW (1990): Planning and spatial working memory following frontal lobe lesions in man. Neuropsychologia 29:9931006

Phelps EA, Hyder F, Blamire AM, Shulma RG (1997): FMRI of the prefrontal cortex during overt verbal fluency. NeuroReport 8:561-565

Reinikainen KJ, Riekkinen PJ, Paljärvi L, Soininen H, Helkala E-L, Jolkkonen J, Laakso M (1988): Cholinergic deficit in Alzheimer's disease: A study based on CSF and autopsy data. Neurochem Res 13:135-146

Riekkinen M, Soininen H, Kuikka J, Laakso M, Helkala E-L, Partanen J, Riekkinen P Jr (1998): Tetrahydroaminoacridine improves the recency effect in Alzheimer disease. Neuroscience 83:471-479
Riekkinen P Jr, Riekkinen M, Soininen H, Kuikka J, Laakso M, Riekkinen P Sr (1997a): Frontal dysfunction blocks the therapeutic effect of THA on attention in Alzheimer's disease. NeuroReport 8:1845-1849

Riekkinen P Jr, Soininen H, Partanen J, Pääkkönen A, Helisalmi S, Riekkinen P Sr (1997b): The ability of THA treatment to increase cortical alpha waves is related to apolipoprotein E genotype of Alzheimer disease patients. Psychopharmacology 129:285-288

Robbins TW, Elliott R, Sahakian B (1996): Neuropsychology-dementia and affective disorders. Br Med Bull 52: 627-643

Rueckert L, Appollonio I, Grafman J, Jezzard P, Johnson R Jr, Le Bihan D, Turner R (1994): Magnetic resonance imaging functional activation of left frontal cortex during covert word production. J Neuroimaging 4:67-70

Sahakian BJ, Owen AM, Morant NJ, Eagger SA, Boddington S, Crayton L, Crockford HA, Crooks M, Hill K, Levy R (1993): Further analysis of the cognitive effects of tetrahydroaminoacridine (THA) in Alzheimer's disease: Assessment of attentional and mnemonic function using CANTAB. Psychopharmacology 110:395-401

Salmon DP, Butters N (1995): Neurobiology of skill and habit learning. Curr Opin Neurobiol 5:184-190

Schwartz BL, Hashtroudi S, Herting RL, Schwartz P, Deutsch SI (1996): d-Cycloserine enhances implicit memory in Alzheimer patients. Neurology 46:420-424

Shimamura AP, Salmon DP, Squire LR, Butters N (1987): Memory dysfunction and word priming in dementia and amnesia. Behav Neurosci 101:347-351

Squire LR (1987): Memory and Brain. New York, Oxford.

Whitehouse P, Price DL, Struble RG, Clark AW, Coyle JT, DeLong RM (1982): Alzheimer's disease and senile dementia: Loss of neuron in the basal forebrain. Science 215:1237-1239

Wilcock GK, Esiri MM (1982): Plaques, tangles and dementia: A quantitative study. J Neurol Sci 56:343-356 